\title{
Calderón y la reescritura de los títulos de comedias
}

\section{Adrián J. Sáez}

\section{Neophilologus}

An International Journal of Modern and Mediaeval Language and Literature

ISSN 0028-2677

Volume 99

Number 2

Neophilologus (2015) 99:223-234

DOI 10.1007/s11061-014-9420-6

\section{Neophilologus}

An international journal

of modern and mediaeval language and literature

Vol. XCIX, No. 2, April 2015

\section{Springer}

ISSN 0028-2677 
Your article is protected by copyright and all rights are held exclusively by Springer Science +Business Media Dordrecht. This e-offprint is for personal use only and shall not be selfarchived in electronic repositories. If you wish to self-archive your article, please use the accepted manuscript version for posting on your own website. You may further deposit the accepted manuscript version in any repository, provided it is only made publicly available 12 months after official publication or later and provided acknowledgement is given to the original source of publication and a link is inserted to the published article on Springer's website. The link must be accompanied by the following text: "The final publication is available at link.springer.com". 


\title{
Calderón y la reescritura de los títulos de comedias
}

\author{
Adrián J. Sáez
}

Published online: 5 December 2014

(C) Springer Science+Business Media Dordrecht 2014

\begin{abstract}
If rewriting is one of the identity signs of Calderón's theatre, it is useful to start from the beginning and examine the occasional revision of his works' titles, because this paratext is the principal presentation card of every text. In this way, this work analyzes the cases in where the title changes between two versions of the play (Amor, honor y poder, La devoción de la cruz, El mayor monstruo del mundo, Guárdate del agua mansa) in order to enquire the fonction of this variation, which could mean a new authorial intent and new perspectives of construction, approach and meaning.
\end{abstract}

Keywords Calderón de la Barca · Title · Rewriting · Intertextuality · Authorial intent

La reescritura es, sin duda, un santo y seña de la dramaturgia de Calderón, que se bifurca en una amplia red de estrategias, con un sinfín de variantes en cuanto a alcance y función. ${ }^{1}$ Es fácil imaginar al poeta sentado en su gabinete rodeado de papeles y echando a volar su imaginación con la ayuda de material tanto propio como ajeno para construir

\footnotetext{
${ }^{1}$ Entiendo por reescritura el fenómeno que se produce cuando es evidente que el poeta $-\mathrm{u}$ otra persona - actúa según una tentativa consciente de reutilizar en su creación — de la forma que sea- la parte o el todo de un texto original. Dentro de este caso extremo de intertextualidad intencionada pueden establecerse diferentes tipologías según varios parámetros, pero baste deslindar entre el trabajo sobre textos propios (auto-reescritura) o ajenos (hetero-reescritura). Más detalles en Vitse (1998) y Sáez (2013);

El presente trabajo se ha beneficiado de los comentarios de mis buenos amigos Noelia Iglesias Iglesias (GIC-Universidade de Santiago de Compostela), Fernando Rodríguez-Gallego (GIC-Universidade de Santiago de Compostela/Universität Wien) y Germán Vega García-Luengos (Universidad de Valladolid). Una primera versión fue presentada en el congreso Calderón en su laboratorio: los manuscritos autógrafos y el proceso de (Viena, 26-27 de mayo de 2014), gracias a la invitación de Wolfram Aichinger y Simon Kroll (Universität Wien).
}

\section{A. J. Sáez $(\bowtie)$}

Institut de Langues et Littératures Hispaniques, Université de Neuchâtel, Espace Louis-Agassiz 1, 2000 Neuchâtel, Switzerland

e-mail: adrian.saez@unine.ch 
sus comedias, ya fuese mediante el reciclaje de micro (giros, imágenes o versos) o macroestructuras (argumentos, escenas y lances), camino que en último término lleva a los textos con dos versiones en una dinámica entre la escena y la imprenta.

Esta técnica fundamental —que no exclusiva— de la fábrica dramática calderoniana comprende algunas pautas constantes que poco a poco se conocen más y mejor: entre otros rasgos, debe destacarse la creciente importancia del decoro (dramático y moral), una cierta búsqueda de la coherencia y la revisión especialmente cuidadosa de los cierres de comedias, lugar clave para la fortuna de un texto (Greer 1984; Carreño 1997; Ulla Lorenzo 2011).

En este sentido, solo pretendo seguir la regla de oro de comenzar por el principio, esto es, por el título, un paratexto esencial que no escapa a la revisión de Calderón, si bien con una frecuencia tal vez un tanto reducida. Y es que el título es la principal tarjeta de visita de todo texto - y obra de arte en general—, un mosaico de signos que adelanta sus rasgos fundamentales y configura el horizonte de expectativas del público, al que trata de seducir con una mezcla de información y misterio (Genette 1987: 59-106; Celaya García 2004). ${ }^{2}$ Al cabo, es también una de las marcas que quedan con más fuerza: basta decir La vida es sueño para despertar el recuerdo de la intriga del príncipe Segismundo y de la errante Rosaura, o hasta posiblemente el eco de la apertura que principia con ese inolvidable «Hipogrifo violento» (v. 1). Que Lope pasara por alto los títulos en su Arte nuevo (1609) no revela acaso sino que la importancia de dar nombre a las comedias era una verdad tan de Perogrullo que no merecía la pena detenerse en ello. Tal parece ser el caso, toda vez que el título es un ingrediente que permanece antes, durante y después del paso por las tablas de las comedias: así ocurre con los carteles que anunciaban las fábulas que se iban a representar (de la Granja 1989); las menciones de los títulos en el cuerpo y el final de los textos (Vara López y Vila Carneiro en prensa), además de las acotaciones y del aval que supone a posteriori la disposición gráfica (letra más gruesa y de mayor tamaño) tanto en partes como - por lo general— en sueltas, en portadas como en titulillos. ${ }^{3}$

Estas premisas invitan a examinar la reescritura de los títulos en el corpus calderoniano. Aunque puede antojarse un detalle baladí que apenas ha merecido comentarios, adelanto ya que los cambios de título en Calderón me parece que constituyen pistas significativas de variaciones de enfoque o de organización del diseño y sentido de las comedias en cuestión.

\section{Nomen est opus: el arte de titular}

En realidad, las presentes reflexiones no hacen sino continuar la interesantísima senda abierta por Iglesias Iglesias $(2010,2014)$ en un par de excelentes trabajos, que

\footnotetext{
Footnote 1 continued

para el caso calderoniano ver especialmente Fernández Mosquera (2010: 34-36) y Rodríguez-Gallego (2010), además de los apuntes constantes que se encuentran en Cruickshank (2011).

${ }^{2}$ No es inocente que las refundiciones tanto coetáneas como decimonónicas prefieran habitualmente mantener el título del hipotexto para valerse de su celebridad.

${ }^{3}$ En el caso de algunas sueltas se encuentran algunas excepiones, pues el título puede aparecer a un tamaño menor que el sintagma «comedia famosa»
} 
enriquecía sobremanera un acercamiento antes centrado en el uso calderoniano de a la cantera de los proverbios para titular sus comedias cómicas. ${ }^{4}$ En ellos ponía sobre la mesa la relevancia que tenían los títulos en la dramaturgia calderoniana como estrategia a la vez estética y comercial:

Calderón era consciente de la importancia de la elección de los títulos de sus comedias. Como consecuencia, el título de cada una de ellas está calculado, pues conforma su primera fase y precisamente por ello la marca de forma singular. [...] Calderón aspiraba, ante todo, a captar la atención del posible consumidor de su producto artístico (ya fuera un espectador o lector potencial). Con cada título debía incitar al público a ir al corral a la representación que se anunciaba o bien a leer su texto. No debe olvidarse, pues, que este móvil late detrás del título de cada una de estas piezas (Iglesias Iglesias 2010: 637-638).

Se trata de un ejercicio libre que solamente debe convenir a la obra, como advierte Carballo (Cisne de Apolo, 1602, p. 283). Al parecer, Calderón seguía las más de las veces una receta similar, que modificaba a su antojo a partir de unos rasgos fundamentales: la brevedad, la sencillez, la información temática esencial y la huella de su estilo (estilema, estructura bi- o trimembre, etc.), todo ello por lo general condensado en un perfecto octosílabo. Asimismo, Iglesias Iglesias deslinda varias categorías según los elementos en juego: (1) títulos-personaje, (2) títulosproverbio, (3) títulos-tema, (4) títulos-sentencia calderoniana, (5) títulos-espacio, (6) títulos-objeto y (7) títulos-tiempo, con diversas trabazones entre sí.

Ahora bien, no siempre es fácil bautizar las comedias. Genette advertía en su día que la vida de los títulos tiene ciertas «nuances, ou entorses» que pueden venir definidas por «les hésitations de l'auteur sur son choix, qui peuvent être fort longues et fort nourries» y que pueden enredarse y prolongarse con la intervención de los agentes editoriales, los adaptadores y finalmente el público, la posteridad (Genette 1987: 70-77). De aquí se deriva la habitual «inestabilidad» de los marbetes calderonianos (Černý 1968: 23-24), que desde luego tiene que ver con la -en ocasiones tortuosa- circulación de los textos dramáticos, pero que al mismo tiempo dice mucho sobre la voluntad autorial del poeta porque, a más de eventuales dudas y vacilaciones, enlaza directamente con su afición reescritora.

En efecto, una mirada a las dos listas «oficiales» de Calderón revela que, en los casos de comedias con dos versiones, el poeta se cuida mucho de recoger solo el título segundo y definitivo. ${ }^{5}$ Se trata a priori de una consecuencia natural del

\footnotetext{
${ }^{4}$ En el segundo ensayo lanza el guante a que se examinen los dobles títulos autoriales, materia de este estudio. Sobre comedias y refranes, ver Canavaggio (1983) y Alviti (2010). Con otro fin, Sullivan (2014: 315-319) comenta la menor frecuencia de poner como título el nombre de personajes frente al drama inglés y francés como reflejo de una diferente concepción de la subjetividad.

5 Situación idéntica al corpus de autos sacramentales (Escudero 2000: 11-12). El primero de los listados fue compendiado por orden real para Carlos II entre 1677 y 1680 y presentada por Francisco Marañón, secretario del patriarca de las Indias, mientras la segunda es una «Memoria de comedias» que Calderón manda con una carta (a 24 de julio de 1680) en respuesta a Pedro Manuel Colón de Portugal, VII duque de Veragua, que fue publicada inicialmente en el Obelisco fúnebre (Madrid, Eugenio Rodríguez, 1684) de Gaspar Agustín de Lara. Pueden verse ambos listados en el catálogo de Reichenberger (1981-2009: vol. 3, 26-31), entre otros lugares. Existe una tercera lista debida a Vera Tassis, con pequeñas modificaciones
} 
proceso de reescritura, pero no es menos cierto que resulta muy significativo, toda vez que la elección del título es una verdadera clave de lectura y este cambio solo se da en contados - y expresivas - casos, porque un repaso de las reescrituras calderonianas revela que se suele mantener el título original, tanto en casos de hetero-reescritura (El alcalde de Zalamea, Argenis y Poliarco, El purgatorio de san Patricio, etc.) como de revisión de composiciones propias (Basta callar, El conde Lucanor, El laurel de Apolo, El mágico prodigioso, La vida es sueño, etc.), y lo mismo vale para los autos sacramentales (El divino Orfeo, Tu prójimo como a ti, etc., con la excepción de La segunda esposa/Triunfar muriendo y El veneno y la triaca/La cura y la enfermedad, más ciertos usos combinados de dos títulos como $E l$ primer refugio del hombre y probática piscina).

Por tanto, esta variatio descubre dos ideas: primero, la reescritura de los nombres de las comedias refleja una decisiva transformación en el sentido y la disposición del texto, más allá de una labor de «limae [...] et mora», que diría Horacio (Ars poética, v. 291); y, de la mano, constituye una táctica consciente y privilegiada para configurar y pulir el legado dramático que se desea fijar. No en vano, no toca títulos tan bien recibidos como La vida es sueño y Vega García-Luengos (2008: 251; 2013: 133, n. 69) ya apunta que el cambio de título era una de las razones por las que Calderón no reconocía alguno de los hijos de su ingenio en su preocupación por dejar en limpio su hoja de servicios poéticos. ${ }^{6}$

\section{Reescrituras menores y significativas}

Queda claro que este retoque en apariencia mínimo puede albergar un sentido más profundo, forjado a partir de un amplio abanico de intereses y motivos, así que merece la pena examinar el mundo de la «reescritura titular», en expresión de Cayuela (2000: 38-39). Para empezar, aclaro que el interés del presente ensayo son los dobles títulos puramente calderonianos y descarto otras parejas de títulos que no muestran la intervención de Calderón: así, dejo de lado (1) las vacilaciones de títulos que pueden darse entre el nombre de la comedia y las menciones en el cuerpo o el final del texto, o entre diferentes testimonios, un caso especialmente peliagudo que levanta acta de sospecha de que algún título no cuente con todas las credenciales calderonianas, sobre todo en textos aparecidos en sueltas y ediciones facticias; y tampoco tengo en cuenta (2) los títulos que solamente da Vera Tassis, pues por mucho que haya quien diga que la responsabilidad del título siempre es compartida entre el autor y el editor, no procede tocar ahora los problemas de títulos de este esforzado agente (ver Genette 1987: 77-78). ${ }^{7}$

\footnotetext{
Footnote 5 continued

desde la Verdadera quinta parte (1682), pero posee menor autoridad a pesar de su esforzada tarea editorial (Vega García-Luengos 2008; Coenen 2009).

6 Sigue a Cotarelo y Mori (2001: 337-338). Ver también los comentarios de Vega García-Luengos (2002).

7 Valga recordar el debate entre El triunfo de la cruz y La exaltación de la cruz, que todavía no se sabe si era una comedia o dos (Vega García-Luengos 2008: 258).
} 
Vacilaciones

El alcalde de Zalamea

El Faetonte

El monstruo de los jardines

Darlo todo y no dar nada

A secreto agravio, secreta venganza

No hay burlas con el amor

De un castigo, tres venganzas

Amar después de la muerte

Ni Amor se libra de amor

La banda y la flor

Nadie fie tu secreto

El príncipe constante

el primer dueto, ver Escudero (1998: 15-16). No consigno en este listado Certamen de amor y celos (perdida), que se ha identificado alternativamente con Amado y aborrecido y con No hay que creer ni en la verdad, pero sin la autoridad suficiente (Vega García-Luengos 2008: 264)

Vera Tassis

Origen, pérdida y restauración de la Virgen del Sagrario

De una causa dos efectos
El garrote más bien dado

El hijo del sol, Faetón

La dama y galán Aquiles

Apeles y Campaspe

Vengarse con fuego y agua

La crítica del amor/La crítica de Madrid

El Tuzaní de la Alpujarra

Psiquis y Cupido

Hacer del amor agravio

No guardes tú tu secreto

El príncipe constante y esclavo por su patria
Un castigo en tres venganzas

En rigor, únicamente la intervención de Calderón es segura - o cuando menos probable - en los casos de comedias con dos versiones, frente al mar de dudas que despiertan los otros puntos. Porque no me interesa el baile de títulos en general, sino justo las razones que tenía Calderón para cambiar el nombre de sus comedias, reescritura que suele acompañar alguna modificación significativa del texto.

Resta así un quinteto de dobles títulos autoriales, fruto de la auto-reescritura calderoniana $^{8}$ :

Títulos con dos versiones

La industria contra el poder

Amor, honor y poder

y el honor contra la fuerza

La cruz en la sepultura

La devoción de la cruz.

El mayor monstruo del mundo

El mayor monstruo, los celos

El agua mansa

Guárdate del agua mansa

La señora y la criada

El acaso y el error

De entrada, dos comedias siguen caminos paralelos, con una primera etapa antes de tener el aval de Calderón: La industria contra el poder y el honor contra la fuerza y La cruz en la sepultura aparecen a nombre de Lope en la espuria Parte XXIII de comedias de Lope (Valencia, Miguel Sorolla, 1629) y la Parte XXVIII de comedias de varios

\footnotetext{
${ }^{8}$ Dejo para mejor ocasión la reescritura externa en los que Calderón remodela una comedia de otro ingenio de la que se distancia —o a la que se aproxima- desde el título, por razones de competencia, homenaje, etc. Vaiopoulos 2010, p. 33, aprecia tres tendencias: (1) conservación para traer a la memoria el hipotexto y beneficiarse de su notoriedad; (2) mantenimiento parcial; y (3) cambio de título y renuncia a mostrar la fuente.
} 
autores (Huesca, Pedro Blusón, 1634) antes de salir como Amor, honor y poder y La devoción de la cruz en las dos primeras partes del poeta (1636 y 1637). Siguen dos ejemplos contrarios: resulta hasta cierto punto curioso el caso de El mayor monstruo del mundo, publicada en la Segunda parte y, ya con otro nombre, después conocido en un manuscrito parcialmente de mano de Calderón (BNE: Res-79) con licencias de 1667 y 1672, mientras que El agua mansa se custodia en un manuscrito autógrafo con censura de 1673 (Biblioteca del Institut del Teatre de Barcelona) y, como Guárdate del agua mansa, aparece en la Octava parte de comedias nuevas (Madrid, Andrés García de la Iglesia, 1657) y en la Octava parte (Madrid, Francisco Sanza, 1684) preparada por Vera Tassis. Con la última pareja se entra en un terreno menos firme: se suele creer que La señora y la criada, presente en la Parte XLVI de la colección de Escogidas (Primavera numerosa de muchas armonías lucientes en doce comedias fragantes, (Madrid, Francisco Sanza, 1679)) y en la Novena parte al cuidado de Vera Tassis, es la segunda redacción de El acaso y el error, que se conoce solo manuscrita, ya que su salida estaba prevista para la Décima y nunca aparecida entrega; sin embargo, todo apunta a la opción contraria según Cruickshank, porque es el único título recogido en las dos listas de Calderón y no sería raro que el resultado final quedase en manuscrito, como se ha visto. ${ }^{9}$ Hay pocas cosas claras y parece más prudente centrarse en los cuatro dobles títulos más autorizados, amén de que sería un título-personaje que evoluciona a un título-tema centrado en los azares del enredo.

Este juego de Calderón con los nombres de las comedias hace buena la importancia que Genette atribuye a la «évolution paratextuelle» (Genette 1987: 67), porque se trata de una transformación de apariencia banal que, no obstante, ofrece pistas sobre los nuevos designios artísticos que alcanzan cuestiones hermenéuticas y a menudo ecdóticas. ${ }^{10}$

1. Un buen botón de muestra para abrir boca es el dueto formado por La industria contra el poder y el honor contra la fuerza y Amor, honor y poder, un retoque temprano que ya abre un haz de sentidos entre el diseño y los lazos intertextuales. Primeramente se aprecia una modificación en la estructura del título, que va unida a la construcción de la comedia: la primera etiqueta refleja una clara contraposición doble - marcada por la estructura paralelística - que da preferencia a la función del ingenio (industria), que tan buenos resultados va a dar a Estela a lo largo de la comedia, mientras que este principio de dualidad desaparece - o se enmascara - en el título luego preferido. ${ }^{11}$ Así, la reescritura calderoniana aboga por una sentencia breve, sencilla y tripartita, que tiene la ventaja de poderse reproducir más fácilmente (en un único verso). También se pasa de un título más centrado en la acción, revelador de las dualidades que acompasan la trama, a otro tal vez más enigmático y

\footnotetext{
9 Ver las ideas de Vega García-Luengos (2008: 259) y Cruickshank (2011: 274, 452 y 455-457) contra la opinión de Romero Blázquez (2007: 13), que aboga por la posterioridad de La señora y la criada, a pesar de que la dinámica suele ser inversa.

10 Ya hay ricas apostillas de Caamaño Rojo (2002, 2006: 54), Vara López (2011) y Vila Carneiro (en prensa), con las que dialogo en lo que sigue.

11 Vara López (2011: 1416, n. 5) escribe: «este título es binario en dos niveles jerárquicos, ya que parte de una estructura coordinada de dos miembros paralelísticos en contraste y cada uno de ellos incluye, a su vez, la oposición por medio de la preposición contra de dos términos que serán muy importantes a lo largo de la comedia».
} 
sin duda más atractivo que se limita a enunciar en sucesión sus principales ingredientes constitutivos. Entre ellos, brilla con luz propia la adición del amor en el rótulo, que con toda intención se presenta en la apertura como signo central en torno al que se articulan los otros dos (honor, poder). Gracias a este nuevo detalle, Amor, honor y poder es paradójicamente un título que resta un tipo de información dispositiva (las oposiciones), a la vez que da otra clave fundamental antes silenciada: el amor. Sin salir del grupo de títulos-tema, por tanto, Calderón ha querido marcar a fuego en el horizonte de expectativas del auditorio el trío de elementos principales de esta comedia en una suerte de gradación jerárquica que, además, se suele tener por la síntesis emblemática de la dramaturgia calderoniana y áurea en general.

A la par, otra razón puede encontrarse en el campo literario (Bourdieau 1992) del momento: según recuerda Vila Carneiro, hay noticia de una comedia perdida de Lope llamada La industria contra el poder (h. 1620), a la que Calderón quizás deseaba hacer un gesto de homenaje - o desafío - desde el título o los versos de una de sus primeras tentativas dramáticas, aunque es igualmente posible que durante su primera etapa impresa — fuera del control del poeta, por cierto — se aprovecharan las referencias textuales para cambiar de título y sacarla a la venta como «de Lope», con el esperado tirón comercial de regalo. ${ }^{12}$ De ser así, cuando llegara la hora de recoger la comedia en la Segunda parte se cambiaría el nombre a Amor, honor y poder no solo por las causas estéticas apuntadas, sino además para reafirmar su autoría y hasta para romper todo nexo con la herencia lopesca, en un momento en el que Calderón ya disfrutaba tanto del aplauso de los mosqueteros como del triunfo en la imprenta. ${ }^{13}$

2. El panorama es algo más complejo con El mayor monstruo del mundo, por otro nombre El mayor monstruo, los celos, ya que también se conocía como El Tetrarca de Jerusalén, título seguramente más claro, pero que nada tiene que ver con Calderón $\mathrm{y}$, por si fuera poco, cuenta entre medias con la intervención de Vera Tassis.

Caamaño Rojo (2002, 2006: 54) mantiene que el título inicial deja un margen mayor de suspense hasta el cierre sobre la identidad del monstruo, mientras el segundo descubre de antemano las cartas a la vez que acentúa la ironía dramática, porque los personajes no alcanzan a descubrir cuál es el mayor monstruo cuando el senado ya lo conoce desde el principio. Conjuntamente, las condiciones materiales y de recepción le hacen dudar de esta presupuesta autoría calderoniana: en efecto, no deja de ser sospechoso que este nuevo título no se mencione - comme il va de soien el texto de la segunda versión, que a su vez se conserva en un manuscrito destinado a la representación, el cual no cuenta más que con la tercera jornada copiada de mano de Calderón y que, para colmo, es propiedad de un autor de comedias, quien acaso estuvo detrás de la modificación del título como un reclamo comercial para presentar una comedia vieja como nueva.

\footnotetext{
12 Vila Carneiro (en prensa) considera la opción de que se tratara de un nuevo caso de reescritura (parcial) de una comedia lopesca.

${ }^{13}$ Paterson (2001) explica el significado social de la publicación de las primeras docenas de comedias calderonianas.
} 
Es verdad que se da nuevo nombre a la tragedia según los nuevos parámetros de recepción (de espacio y público): a nueva vida sobre las tablas, título nuevo para la cartelera, se podría decir. En este caso, la reescritura viene marcada por el salto del corral de comedias a la escena de palacio, por lo que Calderón elimina las bromas de sal gorda y presta más atención al decoro, con la mente puesta en sus nuevos y elevados receptores, y es desde estas coordenadas desde donde se puede enjuiciar el nuevo título, si se da por bueno que puede ser calderoniano o por lo menos tiene el sello de su estilo. ${ }^{14}$ Caamaño Rojo (2002: 443) sugiere entonces que sea una suerte de guiño al predominante público femenino, que se sentiría más atraído por «el posible drama de honor calderoniano» antes que por la calculada ambigüedad de $E l$ mayor monstruo del mundo. Algo de esto es posible que haya, pero la pista principal es una vez más el decoro dramático: lo equívoco del primer título hace que hasta el final pueda entenderse que el monstruo en cuestión podría ser el destino, otras pasiones (el amor, no solo los celos), la muerte o el mismísimo rey Herodes (Sabin 1973). ${ }^{15}$ Pero es que esta posible identificación monstruosa con el monarca cargaría las tintas en exceso sobre el negativo retrato del rey, que debe guardar — como dice Arellano (1994: 23) — unos ciertos límites dentro del decoro trágico, de modo y manera que la labor de aclaración calderoniana en el título vendría a conjurar este peligro de una vez por todas.

3. Menor parece el cambio de El agua mansa a Guárdate del agua mansa, con la única adición de la forma verbal. No tiene nada que ver con las razones de esta reescritura, que se adapta a las circunstancias históricas para celebrar las bodas reales de Felipe IV y Mariana de Austria en dos extensas relaciones injertadas en la comedia con cierta premura. ${ }^{16}$ En cambio, el nuevo título quiere acercarse a las fórmulas más conocidas del refrán en que se inspira, como «Dios me guarde del agua mansa, que yo me libraré de la brava» (Correas, núm. 7221) o «Del agua mansa me guarde Dios, que de la brava yo me guardaré» (Mal Lara, Filosofía vulgar, I, 72, pp. 509-510), entre otras, que antes se daba muy abreviado. Dar un aire de novedad tenía que ser un motivo a la luz de las prisas que le apremiaban, pero no es menor el espaldarazo que siempre da el refranero. Con ello, Calderón expresa más claramente el sentido de la acción: hay que cuidarse de las aguas tranquilas porque pueden esconder peligrosas profundidades, lo que en términos de la acción se vuelve en prudente advertencia contra las damas ingeniosas que se disfrazan de mansedumbre. Así lo confirma García Santo-Tomás (2004: 641), para quien se está expresando una recomendación de cuidado o una invitación a aprender respecto a una táctica de comportamiento. ${ }^{17}$ Con Guárdate del agua mansa, al fin, el

\footnotetext{
14 Tanto el mundo (El diablo mundo, El gran mercado del mundo, El gran teatro del mundo) como los celos (Celos aun del aire matan) constan en otros rótulos del poeta.

15 Aunque a la postre resulte claro que se trata de los celos, la diversidad de públicos facilitaba esta ambigüedad.

16 Ver Arellano (1986); Arellano y García Ruiz (1989: 29-41 y 53-79) que nada dicen del título; tampoco en Arellano (1986).

17 Precisa: «este "guárdate" que advierte el título parece ser más un "aprende" que un "ten cuidado", y el adjetivo "manso" puede leerse más como una táctica a emplear que como un simple epíteto irónico» (2004: 641).
} 
poeta se aprovecha del apoyo de la sentencia popular y pone de manifiesto una clave de lectura.

4. He dejado para el cabo un caso parejo que da pie a una red mayor de intereses: el par que arman La cruz en la sepultura y La devoción de la cruz. Dentro de la tipología de Iglesias Iglesias (2010: 640), constituye el desplazamiento de un título-espacio (u objeto) a un título-tema: del inicial valor situacional, porque presenta el lugar (la sepultura) donde muere y se salva Eusebio, se pasa al sentido más doctrinal (devoción) del segundo. Este nuevo nombre de la comedia es menos enigmático o trivial, en tanto ofrece la información temática esencial, con lo que evita ambigüedades y destaca «el implícito valor didáctico» de la comedia ya desde el título, como opera con piezas de santos o personajes bíblicos (valga Judas Macabeo). ${ }^{18}$

En esencia, esta reelaboración calderoniana busca aclarar el sentido de la comedia ab initio $^{19}$ : para ello, el poeta calla el adelanto del final trágico del personaje, que podía jugar en su contra por revelar más de lo necesario en un primer momento, y se preocupa especialmente por perfilar el carácter sacro de la comedia alrededor de la devoción. Si se quiere, se trata de un giro que insiste más en los méritos de Eusebio (causas) que en su muerte (fin); esto es: Calderón silencia el aviso sobre su muerte para dar preferencia a la virtud que otorga el carácter milagroso de esta conclusio. Al mismo tiempo, se pretende encauzar la lectura de la comedia hacia su sentido religioso, tan criticado en ocasiones por los lectores de ayer y hoy. Más en detalle, este nuevo marbete casa bien con la reescritura de Calderón, que perfila dos puntos clave de la comedia: la importancia del símbolo de la cruz y del sacramento de la confesión, muy relevantes en la apoteosis final.

Un buen número de correcciones amplían la función que la cruz tiene en el drama: frente a La cruz en la sepultura, en La devoción de la cruz se añade la noticia de la marca en forma cruz en el pecho de Julia como prueba de la intervención divina desde su nacimiento (vv. 1377-1387) y se desarrolla con lujo de detalles cómo este signo corta la acometida de Eusebio e impide in extremis la consumación del incesto (vv. 1596-1620). Este segundo cambio concede coherencia al diseño dramático, ya que se une a otras referencias posteriores sobre el proceso de anagnórisis (vv. 1812-1815), y principalmente rubrica la devoción interesada de Eusebio por la cruz, que confiesa en unos versos nuevos (vv. 1600-1615):

Señal prodigiosa ha sido, y no permitan los cielos que aunque tanto los ofenda pierda a la cruz el respeto; porque si la hago testigo de las culpas que cometo, ¿con qué vergüenza después llamarla en mi ayuda puedo? (vv. 1608-1615)

\footnotetext{
18 Reviso aquí algunas ideas de Sáez (2014: 139, 161-167 y ver 48-58).

19 A decir de Ruano de la Haza (1998: 35-36 y 45), es una técnica por la que un dramaturgo más maduro «pule, perfecciona, afina y modifica un texto teatral para crear una nueva versión», no destinada para los corrales, al tiempo que buscaba reparar el deturpado estadio textual en que circulaba la comedia.
} 
En cuanto a la confesión, Calderón añade una primera muestra en el duelo inicial entre Eusebio y Lisardo, cuando este pide misericordia antes de recibir el golpe de gracia: si en la primera versión se ampara en «aquella/cruz en que Cristo murió» (vv. 376-377), en la segunda también solicita poder confesarse («iNo me permitas que muera/sin confesión!», vv. 374-375). A más de una señal del alcance de este sacramento, esta adición constituye el primer eslabón de una cadena de menciones posteriores: se corresponde con la promesa posterior de Lisardo («si yo merezco verme/en la divina presencia/de Dios, pediré que tú/sin confesarte no mueras», vv. 397-400), con la petición de Eusebio a Alberto («Si deseas/mi bien, pídele a Dios que no permita/muera sin confesión», vv. 1020-1022), con el recuerdo de ambas acciones en su muerte (vv. 2306-2315) y el milagro final, por el que el alma de Eusebio permanece en su cuerpo hasta que puede confesarse para morir ejemplarmente. En suma: el verdadero interés de este cambio de título está en que marca un patrón de revisión que Calderón desarrolla durante la reescritura.

\section{Final: cartografía de revisión}

No se sabe si en el principio es la idea o el título. En cualquier caso, la reescritura de los títulos demuestra la importancia de dar un buen nombre a las comedias para Calderón, que se preocupaba de perfeccionar este detalle paratextual cuando volvía sobre sus composiciones. El repaso descubre ya ciertas pautas de este ejercicio de revisión sustentado en causas externas e internas: primeramente, Calderón se vale de los cambios de título para reafirmar su autoría y recuperar el control de sus textos, en comedias que han sido atribuidas a Lope $\mathrm{u}$ otros ingenios en impresos poco fiables (Amor, honor y poder, La devoción de la cruz); al mismo tiempo, insiste en su gusto por el octosílabo (Amor, honor y poder, Guárdate del agua mansa) frente a formas que pecan por exceso o por defecto) y trata de ofrecer el mayor número de claves posibles al auditorio desde el principio, para lo que aclara los temas principales, evita equívocos (El mayor monstruo, los celos) y apunta el valor didáctico de la acción, a veces con la ayuda de una sentencia; con todo y ello, el ejemplo de La cruz en la sepultura y La devoción de la cruz refleja con especial fortuna la fuerte relación que une a la reescritura del título con el proceso de revisión.

Visto lo visto, se puede acabar con algunas palabras sobre ciertos casos controvertidos o dudosos: quizás un argumento más en contra de la autoría calderoniana de la versión manuscrita de El príncipe constante (BNE: Mss/15159) sea que su título (El príncipe constante y esclavo por su patria) excede con mucho la medida octosilábica tan cara a Calderón y nada contra el habitual recorte de los segundos nombres de los textos. ${ }^{20}$ Así se podría seguir con otros ejemplos, porque el título es un factor más que, desde el incipit, dice mucho sobre la comedia en cuestión, sí, pero también sobre los designios del poeta y su reescritura.

\footnotetext{
$\overline{20}$ Hernando Morata (2012) no se refiere a este aspecto. A propósito del público, Genette (1987: 74) ya establecía la frecuencia de esta dinámica : «[s]on travail —ou plutôt, en l'occurrence, sa paresse— va généralement dans le sens d'un raccourcissement, d'une véritable érosion du titre».
} 


\section{Bibliografía}

Alviti, R. (2010). Calderón y el refranero. Anuario Calderoniano, 3, 23-36.

Arellano, I. (1986). Las dos versiones de una comedia de Calderón: El agua mansa y Guárdate del agua mansa. Criticón, 35, 99-118.

Arellano, I. (1994). Sobre las lecturas trágicas calderonianas: El mayor monstruo del mundo (notas para una síntesis del drama). En: I. Arellano (Ed.), Del horror a la risa: los géneros dramáticos clásicos (pp. 9-41). Kassel: Reichenberger.

Arellano, I., \& García Ruiz, V. (Ed.) (1989). P. Calderón de la Barca, El agua mansa. Guárdate del agua mansa. Granada/Kassel: Universidad de Granada/Reichenberger.

Bourdieu, P. (1992). Les règles de l'art: genèse et structure du champ littéraire. Paris: Seuil.

Caamaño Rojo, M. J. (2002). Notas al título de una tragedia calderoniana. En: R. Lorenzo (Ed.), Homenaxe a Fernando R. Tato Plaza (pp. 435-445). Santiago de Compostela: Universidade de Santiago de Compostela.

Caamaño Rojo, M. J. (Ed.) (2006). P. Calderón de la Barca, El mayor monstruo del mundo. Santiago de Compostela: Universidade de Santiago de Compostela. [Tesis doctoral inédita en CD-Rom].

Canavaggio, J. (1983). Calderón entre refranero y comedia: de refrán a enredo. En: K. Körner y D. Briesemeister (Ed.), Aureum Saeculum Hispanum. Beiträge zu Texten des Siglo de Oro. Festschrift für Hans Flasche zum 70. Geburtstag (pp. 27-35). Wiesbaden: Franz Steiner.

Carballo, L. A. de (1997). Cisne de Apolo, Ed. A. Porqueras Mayo. Kassel: Reichenberger.

Carreño, A. (1997). The poetics of closure in Calderón's plays. En: M. Delgado Morales (Ed.), Calderonian Stage: Body and Soul (pp. 25-44). Lewisburg: Bucknell University.

Cayuela, A. (2000). De reescritores y reescrituras: teoría y práctica de la reescritura en los paratextos del Siglo de Oro. Criticón, 79, 37-46.

Celaya García, M. (2004). El título en la literatura y en las artes. Pamplona: Eunsa.

Černý, V. (Ed.) (1968). P. Calderón de la Barca, No hay que creer ni en la verdad. Madrid: CSIC.

Coenen, E. W. (2009). En los entresijos de una lista de comedias de Calderón. Revista de Filología Española, 89(1), 29-56.

Correas, G. (2000). Vocabulario de refranes y frases proverbiales, Ed. digital R. Zafra. Pamplona: Universidad de Navarra, 2000. [CD-Rom].

Cotarelo y Mori, E. (2001). Ensayo sobre la vida y obras de D. Pedro Calderón de la Barca, Ed. facsímil I. Arellano y J. M. Escudero. Madrid/Frankfurt: Iberoamericana/Vervuert.

Cruickshank, D. W. (2011). Calderón de la Barca. Su carrera secular, trad. J. L. Gil Aristu. Madrid, Gredos. [Original: Don Pedro Calderón. Cambridge: Cambridge University Press, 2009].

de la Granja, A. (1989). Cosme, el que carteles puso. A propósito de un actor y su entorno. En: Homenaje al profesor Antonio Gallego Morell (vol. 2, pp. 91-108). Granada: Universidad de Granada.

Escudero, Juan M. (Ed.) (1998). P. Calderón de la Barca, El alcalde de Zalamea. Madrid/Frankfurt: Iberoamericana/Vervuert.

Escudero, Juan M. (Ed.) (2000). P. Calderón de la Barca, El veneno y la triaca. Pamplona/Kassel: Universidad de Navarra/Reichenberger.

Fernández Mosquera, S. (2010). Reescritura en el Siglo de Oro: diferentes estrategias autoriales. En: I. Arellano y S. Bagnó (Ed.). El siglo de Oro español: texto e imagen (Congreso Internacional, GRISO/Ermitage, San Petersburgo) (pp. 23-37). Pamplona: Eunsa.

García Santo-Tomás, E. (2004). Calderón y las aguas revueltas de Guárdate del agua mansa. Arbor, 177.699-700 (639-648).

Genette, G. (1987). Seuils. Paris: Seuil.

Greer, M. R. (1984). Calderón, copyists, and the problem of endings. Bulletin of the Comediantes, 36(1), 71-81.

Hernando Morata, I. (2012). En torno al texto de El príncipe constante, de Calderón: el manuscrito 15.159 de la BNE. Boletín de la Biblioteca de Menéndez Pelayo, 88.2, 197-234.

Horacio (1989). Ars poetica, en Epistles, II, Ed. N. Rudd. Cambridge: Cambridge University Press.

Iglesias Iglesias, N. (2010). «De los títulos y nombres que se han de poner a las poesías»: tres tipos de títulos en las comedias de Calderón. En: G. Vega García-Luengos y H. Urzáiz Tortajada (Ed.), Cuatrocientos años del «Arte nuevo de hacer comedias» de Lope de Vega. Actas selectas del XIV Congreso de la Asociación Internacional de Teatro Español y Novohispano de los Siglos de Oro (Olmedo, 20 al 23 de julio de 2009) (pp. 635-644). Valladolid/Olmedo: Universidad de Valladolid/ Ayuntamiento de Olmedo. [CD-Rom]. 
Iglesias Iglesias, N. (2014). Hacia una taxonomía de los títulos de comedias de Calderón. Bulletin of Hispanic Studies, 91(3), 243-260.

Mal Lara, Juan de (2013). La filosofía vulgar, Ed. I. Pepe Sarno y J. M. ${ }^{a}$ Reyes Cano. Madrid: Cátedra.

Paterson, A. K. G. (2001). La socialización de los textos de Calderón. El legado de don Juan de Vera Tassis y don Pedro de Pando y Mier. En: I. Arellano y G. Vega García-Luengos (Ed.), Calderón: innovación y legado. Actas selectas del IX Congreso de la Asociación Internacional de Teatro Español y Novohispano de los Siglos de Oro, en colaboración con el Grupo de Investigación Siglo de Oro de la Universidad de Navarra (Pamplona, 27 al 29 de marzo de 2000) (pp. 17-29). New York: Peter Lang.

Reichenberger, K. R. (1981-2009). Manual bibliográfico calderoniano. Kassel: Verlag Thiele und Schwartz/Reichenberger, 4 vols.

Rodríguez-Gallego, F. (2010). Aproximación a la reescritura de comedias de Calderón de la Barca. En: N. Fernández (Ed.), «Como en la antigua, en la edad nuestra». Presencia de la tradición en la literatura española del Siglo de Oro (pp. 157-193). Barcelona: Universidad Autónoma de Barcelona/Prolope/TC/12.

Romero Blázquez, C. (2007). Estudio, edición crítica y anotación de dos comedias palatinas de Calderón: «La señora y la criada» y «El acaso y el error». Pamplona: Universidad de Navarra. [Tesis doctoral inédita].

Ruano de la Haza, J. M. (1998). Las dos versiones de El mayor monstruo del mundo, de Calderón». Criticón, 72, 35-47.

Sabin, E. R. (1973). The Identities of the Monster in Calderón's El mayor monstruo del mundo. Hispania, 56, 269-275.

Sáez, A. J. (2013). Reescritura e intertextualidad en Calderón: No hay cosa como callar». Criticón, 117, $159-176$.

Sáez, A. J. (Ed.). (2014). P. Calderón de la Barca, La devoción de la cruz. Madrid/Frankfurt: Iberoamericana/Vervuert.

Sullivan, H. W. (2014). Lacan and tragic drama in the Golden Age of Spain. En: H. Kallendorf (Ed.), $A$ companion to early modern hispanic theater (pp. 311-335). Brill: Leiden/Boston.

Ulla Lorenzo, A. (2011). Sobre la reescritura de los finales en las comedias de Calderón: Polifemo y Circe (1630) y El mayor encanto, amor (1635 y 1668). En: A. Azaustre Galiana y S. Fernández Mosquera (coord), Compostella aurea. Actas del VIII Congreso de la Asociación Internacional del Siglo de Oro (Santiago de Compostela, 7-11 de julio de 2008). (vol. 3, pp. 485-496). Santiago de Compostela: Universidade de Santiago de Compostela.

Vaiopoulos, K. (2010). De la novela a la comedia: las «Novelas ejemplares» de Cervantes en el teatro del Siglo de Oro. Vigo: Academia del Hispanismo.

Vara López, A. (2011). Del concepto a la forma: la dualidad en Amor, honor y poder. En: A. Azaustre Galiana y S. Fernández Mosquera (Eds., coord.), Compostella áurea. Actas del VIII Congreso de la Asociación Internacional Siglo de Oro (Santiago de Compostela, 7-11 de julio de 2008) (vol. 3, pp. 507-512). Santiago de Compostela: Universidade de Santiago de Compostela.

Vega García-Luengos, G. (2002). El Calderón apócrifo. En: I. Arellano (Ed.), Calderón 2000. Homenaje a Kurt Reichenberer en su 80 cumpleaños: Actas del Congreso Internacional IV Centenario del nacimiento de Calderón (Universidad de Navarra, septiembre, 2000) (vol. 2, pp. 887-904). Kassel: Reichenberger.

Vega García-Luengos, G. (2008). Consideraciones sobre la configuración del legado de comedias de Calderón. Criticón, 103-104, 249-271.

Vega García-Luengos, G. (2013). El Calderón que olvidó o repudió Calderón. En: A. Bègue y E. Herrán Alonso (Ed.). Pictavia áurea. Actas del IX Congreso de la Asociación Internacional Siglo de Oro (Poitiers, 11-15 de julio de 2011) (pp. 111-142). Toulouse: PUM.

Vitse, M. (Ed.) (1998). Siglo de Oro y reescritura. I: Teatro, Criticón, 72.

Vara López, A., \& y Vila Carneiro, Z. (en prensa). «Y con esto se da fin»: fórmulas estereotipadas y metatreatalidad en los cierres de las comedias calderonianas.

Vila Carneiro, Z. (Ed.) (en prensa). P. Calderón de la Barca, Amor, honor y poder. Madrid/Frankfurt: Iberoamericana/Vervuert. 